\title{
Two currencies, one model? Evidence from the Wall Street Journal forecast poll
}

\author{
Michael Frenkel, Jan Ruelke and Georg Stadtmann
}

October 2005

\begin{abstract}
We use the foreign exchange forecasts of the Wall Street Journal poll to compare forecasters' expectation formation process for the exchange rates of the euro and the yen against the U.S. dollar for the period 1999 - 2005. We also contrast the expectation formation process with the actual exchange rate process. We find that most forecasters have stabilizing exchange rate expectations, but our results also suggest significant heterogeneity between forecasters. Compared to the forecasters' expectations the actual exchange rate process of the yen/dollar exchange rate is more stable than expected, while the euro/dollar exchange rate exhibit positive autocorrelation.
\end{abstract}

JEL classification: F31, D84, C33

Keywords: Foreign exchange market, forecast bias, random walk

\section{Address:}

WHU Koblenz

Otto Beisheim Graduate

School of Management

Burgplatz 2

56179 Vallendar

Germany
Tel: $+49 / 261 / 6509-280$

Fax: $+49 / 261 / 6509-279$

e-Mail: michael.frenkel@whu.edu 


\title{
Two currencies, one model? Evidence from the Wall Street Journal forecast poll
}

October 2005

\begin{abstract}
We use the foreign exchange forecasts of the Wall Street Journal poll to compare forecasters' expectation formation process for the exchange rates of the euro and the yen against the U.S. dollar for the period 1999 - 2005. We also contrast the expectation formation process with the actual exchange rate process. We find that most forecasters have stabilizing exchange rate expectations, but our results also suggest significant heterogeneity between forecasters. Compared to the forecasters' expectations the actual exchange rate process of the yen/dollar exchange rate is more stable than expected, while the euro/dollar exchange rate exhibit positive autocorrelation.
\end{abstract}

JEL classification: F31, D84, C33

Keywords: Foreign exchange market, forecast bias, random walk 


\section{Introduction}

Knowing how expectations are formed in the foreign exchange market is crucial to understanding how this market works. In empirical studies of exchange rate models, the joint hypothesis of the validity of the examined model and rational expectation is tested. Hence, one of the reasons why empirical studies often find little empirical support for the investigated exchange rate model could be the violation of the rational expectation assumption in the foreign exchange market. Indeed, a number of studies have raised doubts about the validity of the rational expectations assumption in this market (e.g., Frankel and Froot, 1987a; Frankel and Rose 1995; Menkhoff 1998, 2001). Another assumption of traditional exchange rate models is that participants in the foreign exchange market can be viewed as homogenous. However, studies on the micromarket structure suggest that there might be different groups of traders acting in the foreign exchange market. This led several theorists to develop models in which the rational expectation assumption is relaxed and different types of actors in the currency market are considered (e.g., Frankel and Froot, 1987b; DeLong et al., 1990).

In this paper, we examine the Wall Street Journal (WSJ) poll to compare the characteristics of the expectation formation process in two different foreign exchange markets. The WSJ data enables us to perform this comparison, because a few years ago it started to conduct surveys not only for the euro/dollar market, but also for the yen/dollar market. We therefore apply the results of this survey to shed light on two aspects of the expectation formation process. The first aspect refers to the question whether the same expectation formation process applies to both currencies. The second aspect deals with the question whether there are differences with respect to the homogeneity or heterogeneity of foreign exchange market traders. 
The main advantage of the WSJ data set is that we can observe exchange rate expectations of a large number of individual forecasters and not only the mean or median of a group of forecasters. This feature allows us to analyze both the time series characteristics and the cross-sectional characteristics of the data set by applying panel econometric methods. The possibility to observe individual expectations distinguishes the WSJ data set from other data sets like the one compiled by Reuters and used by Leitner/Schmidt/Bofinger (2003). Another advantage of the WSJ data set is that the poll has been conducted for several years (since 1989 for the yen/dollar exchange rate and since 1999 for the euro/dollar exchange rate). By contrast, the study of Ito (1990) - who also operates with individual data - covers only the time period May 1985 - June 1987. Hence, the time dimension in Ito (1990) is limited to a two year horizon. The data set of Ito (1990) is updated by Elliott/Ito (1999) and covers the period May 1985 - May 1996. They test whether FX forecasts can be used as a trading rule. Excess profits generated by this rule are on average larger than the profits of a random walk forecast. However, profits that could have been earned are highly variable. This aspect underlines that there is a significant risk in using these strategies.

The remainder of the paper is structured as follows. In the next section, we characterize the WSJ data set. In Section 3, we examine the question whether expectations were formed rationally. In Section 4, we investigate the expectation formation process. In section 5, we compare the characteristics of the expectation formation process in the euro/dollar and the yen/dollar market in more detail. In section 6, we summarize our findings and present some conclusions. 


\section{The WSJ data set}

The WSJ regularly asks financial market participants to forecast several financial variables for a six month horizon. The survey is published biannually in the beginning of January and July. When the survey was launched in 1981, the focus was on the expected developments of short and long term interest rates. While the survey was initially limited to 12 participants, it increased to a maximum of 64 participants in January 1996 and has been very stable around 55 participants since 1997.

Over time, the number of economic variables covered by the survey increased considerably. For example, since January 1995, survey participants have also been requested to forecast real GDP growth rates and inflations rates. However, two changes that have been implemented since the launch of the survey are of particular interest for our analysis. First, since 1989, the survey includes a six-month forecast for the yen/U.S. dollar exchange rate. Second, in mid-1999, the WSJ added a six-month forecast for the euro/U.S. dollar exchange rate.

The WSJ data set has already been used in some other studies, but those focus on other questions than our analysis. Greer (2003) concentrates on the one-year forecast of the 30 year U.S. Treasury bond. He examines whether economists are able to predict the direction of change correctly and finds some evidence that this is indeed the case. Cho and Hersch (1998) analyze whether the characteristics of forecasters contribute to explain the forecast accuracy (i.e., the size of error) and/or the forecast bias (i.e., the sign of the error). While the authors do not find that the characteristics of the forecasters can explain forecast accuracy, some characteristics like the professional experience of the forecasters with the Federal Reserve System seem to be able to explain forecast direction error. Kolb and Stekler (1996) 
test whether there exists a consensus among WSJ forecasters. The results suggest the existence of a high degree of heterogeneity, so that central moments should not be used as consensus predictions. Eisenbeis, Waggoner and Zha (2002) question the methodology used by the WSJ to construct an overall ranking of the polled economists. Since the WSJ ranks the forecasts on the sum of the weighted absolute percentage deviation from the actual realized value of each series, this methodology neglects the correlations among the variables being forecast.

Our study focuses on the expectation formation process in the foreign exchange market and uses the semi-annual forecasts surveys of the WSJ data set. As we compare the forecasts for the euro/dollar and the yen/dollar exchange rate and as the former has been included in the survey only since mid-1999, our analysis covers the time span of July 1999 - January 2005, i.e., 12 periods. During this time, altogether 84 economists participated in the WSJ survey. Hence, our data set is an unbalanced panel. Figure 1 presents an illustration of how many times the different forecasters participated in the poll. For example, while five economist participated in only one poll, 26 economist participated in all polls. In order to investigate the time series characteristics of the expectation formation process of the participants, we need to apply a minimum participation frequency of each forecaster. Therefore, we only include those forecasters in our analysis, who participated at least seven times during the period July 1999 - January 2005 in the WSJ poll. This applies to 50 forecasters of the WSJ data set.

\section{Insert Figure 1 here}

The WSJ data set has several advantages over other surveys and is, thus, less subject to some of the weaknesses often associated with survey data. First, the individual forecasts are published together with the names of the forecasters. Given that this allows everybody to evaluate the performance 
of the individual participants, the goodness of the forecasts can be expected to have an effect of the reputation of the forecasters. This should increase the incentives of the all participants in the survey to submit their very best rather than strategic forecast (see Keane/Runkle 1990). ${ }^{1}$ Second, unlike some other surveys, forecasters participating in the WSJ poll do not only submit the direction of the expected exchange rate change, but forecast a specific exchange rate level. Third, the survey data are readily available to the public so that our results can easily be verified.

\section{$3 \quad$ Tests for rationality of expectations}

We begin our analysis by examining the question whether expectations are formed rationally. We follow Ito (1990), MacDonald and Marsh (1996), and Elliot and Ito (1999) in applying two criteria: unbiasedness and orthogonality. To investigate whether the forecasts represent unbiased predictors of future exchange rates, we estimate

$$
s_{t+1}-s_{t}=\alpha+\beta\left(E_{i, t}\left[s_{t+1}\right]-s_{t}\right)+\epsilon_{i, t+1}
$$

Unbiasedness prevails if $\alpha=0$ and $\beta=1$. In this case, exchange rate changes are not necessarily forecasted accurately, but the forecast errors do not show any systematic pattern. In a first step, we estimate equation (1) by using a pooled OLS model. The results - summarized in Table 1 - indicate that the constant, i.e., $\alpha$ is significantly different from zero and $\beta$ is different from unity for both currencies. The results imply that expectations are not an unbiased predictor of the future exchange rate. We also checked whether person specific constants exist by using a fixed effects

\footnotetext{
${ }^{1}$ In contrast to the view of Kean/Runkle (1990), Laster/Bennett/Geoum (1999) develop a model where forecasters are rewarded for forecast accuracy (in statistical terms) as well as by publicity in case of giving the best forecast at a single point in time. As a consequence those forecasters will differ most from consensus forecast whose wages depend most on publicity.
} 
model, but the test statistic did not indicated differences between individuals.

The test for orthogonality examines whether forecast errors are unrelated to information on exchange rate changes available at the time of forecasting. As a representation for the latter we use, for simplicity, the exchange rate change compared to the previous period. Hence, we estimate

$$
s_{t+1}-E_{i, t}\left[s_{t+1}\right]=\alpha+\beta\left(s_{t}-s_{t-1}\right)+\epsilon_{i, t+1}
$$

Orthogonality implies that $\alpha=0$ and $\beta=0$ so that neither a constant nor the exchange rate return of the past period can explain the forecast error. In a first step, we estimated again a pooled OLS model and checked afterwards whether the assumption of a single constant is valid. As the results in Table 2 indicate, both $\alpha$ and $\beta$ are significantly different from zero for both currencies. In a second step we run a fixed effects model and checked the assumption of a single constant. While the assumption of a single constant is valid in the case of the Yen, this hypothesis is rejected for the euro exchange rate. A Hausman specification test let to the conclusion, that a random effects model is more appropriate than the fixed effects model. As a consequence Specification IV is our preferred specification for the euro exchange rate. However, this finding does not change our argumentation with respect to the orthogonality condition which is neither met in the yen nor in the euro.

Hence, concluding from estimating equations (1) and (2), the forecasts of the participants of the WSJ poll do not seem to support the hypothesis of rational expectations. For this reason, we study in more detail the expectation formation process in the next section. 


\section{Examination of the expectation formation process}

In this section, we examine the expectation formation process by comparing actual exchange rate developments and expectations about future exchange rates. Figure 2 illustrates for both the dollar/euro (left vertical scale) and the yen/dollar exchange rate (right vertical scale) the actual exchange rate at a particular point in time, et, and the six month forecast for the this exchange rate, $E_{t}\left(s_{t+1}\right)$. While the solid line shows the mean of the exchange rate forecasts, the dashed line shows the actual exchange rate. The impression that Figure 2 conveys is that the mean of the forecasts follows the actual exchange rate, because in most cases the mean six month forecast does not deviate substantially from the exchange rate at the time of the forecasts.

Insert Figure 2 here

In order to compare exchange rate expectations in both markets, Figure 3 shows the expectation of each individual $i$, i.e., $E_{i, t}\left[s_{t+1}\right]-s_{t}$ (with $i=$ individual forecaster), for all periods included in the data set. The plot suggests two characteristics. First, the different points are grouped around the point of no expected exchange rate changes. This confirms the impression from Figure 2 according to which expectations follow actual exchange rate developments. Second, the plot points to a negative slope which means that whenever forecasters expect, say, the yen to appreciate against the U.S. dollar (reflected in a negative value on the horizontal axis) they expect the euro to appreciate against the U.S. dollar too (reflected in a positive value on the vertical axis).

Insert Figure 3 and Table 2 here

We now examine the expectation formation process in more detail. We begin by investigating whether the data support the hypothesis that market participants have extrapolative expectations. Given the structure of the WSJ 
survey, this would be the case if the expected exchange rate change is a function of the exchange rate developments of the past period, i.e., six months. More specifically, we estimate the following expectation formation process:

$$
E_{i, t}\left[s_{t+1}\right]-s_{t}=\alpha+\beta\left(s_{t}-s_{t-1}\right)+\epsilon_{i, t} .
$$

Here, $s_{t}$ and $E_{t}$ denote the log of the exchange rate and the expectation operator at time $t$, respectively. In addition, subscript $i$ denotes the individual forecaster and $\epsilon$ the error term. If we find that $\beta$ is positive this would indicate that whenever the euro, say, depreciates traders expect a further depreciation. In this case, expectations can be said to be destabilizing. However, if $\beta$ is estimated negative this would indicate that a depreciation of the euro during the period preceding the time of the forecast leads market participants to expect an appreciation during the next period. In this case, expectations can be said to be stabilizing.

Assuming the same constant for all forecasters, we apply a fixed effects model to estimate equation (1) and show the results for the group of forecasters as a whole in Table 2. The estimates imply that for the exchange rate of both the euro and the yen, forecasters form mean reversion expectations. Both slope coefficients are significant at the 1 percent level. However, the expected process is somewhat stronger for the euro than for the yen. More specifically, if the euro depreciated by 10 percent during the last six months, forecasters expect a 2.1 percent appreciation over the next 6 months. By contrast, if the yen depreciated by 10 percent in the preceding period forecasters expect only a .7 percent appreciation within the next 6 months. Thus, forecasters anticipate a stronger stabilizing process for the euro than for the yen.

Insert Table 3 here

As a next step of our analysis, we examine the differences in the expectation formation process of individual forecasters. To this end, we apply the same 
regression as before, but now estimate an individual slope coefficient for each forecaster. In order to present our results in a concise way, we plot the individual slope coefficients for each forecaster in Figure 4. Each point in this scatter diagram depicts the combination of the estimated individual slope coefficient for the euro (horizontal axis) and for the yen (vertical axis) of one forecaster. The vertical and horizontal dashed line show the estimates for the forecaster group as a whole presented in Table 3. Figure 4 reveals three main results.

- First, the slope coefficients differ considerably so that currency forecasters can be viewed as heterogeneous. This confirms former research by Benassy-Quere/Larribeau/MacDonald (2003). As the variables used (actual and past exchange rate) in the approach are available to all forecasters at virtually no costs, MacDonald and Marsh (1996) would define this as evidence of differences in the forecasting models.

- Second, while most forecasters have a negative slope coefficient and form therefore stabilizing expectations, several of the forecasters are estimated to have positive slope coefficients for at least one currency, some individuals even for both currencies.

- Third, there is a similarity between the slope parameters of individual forecasters and the slope parameters of the group, i.e. their average. When the slope parameter of the individual forecaster is higher than the group for one exchange rate, it is in most cases also higher than the group average for the other exchange rate. This is indicated by the numbers shown in four areas into which the dashed lines divide Figure 4.

A total of 20 forecasters who have higher-than-average $\beta$ values for the euro, also have higher-than-average $\beta$ values for the yen and 14 forecasters who have lower-than-average $\beta$ values for the euro also have lower-than-average $\beta$ 
values for the yen. However, the number of forecasters with higher values in the euro case and lower values for the yen case and vice versa are only 9 and 7, respectively. Another way to put this feature is the following: A regression line running through the intersection of the dashed lines has a positive slope of 0.44 , with the slope coefficient being significantly different from zero on a $1 \%$ confidence interval. The interpretation of this result is straight forward: When forming their expectations, forecasters tend to apply a similar model to both exchange rates.

\section{Insert Figure 4 here}

Is there a correlation between the individual slope coefficients of each forecasters and their forecast accuracy? Figure 5 suggests such a relationship for the exchange rate of the euro vis-à-vis the dollar. The diagram shows the estimated individual slope coefficients value of individual forecasters and the vertical axis shows the accuracy of the forecasts calculated by the mean squared error. The scatter diagram implies that the higher a forecaster's individual slope coefficient is, the more accurate is also his forecast.

Insert Figures 5 and 6 here

The relationship between the individual slope coefficients and the forecast accuracy does not hold for the exchange rate of the yen vis-à-vis the U.S. dollar. As Figure 6 indicates, the forecast error seems to be independent of the slope value.

A more detailed analysis of the forecast errors confirms the impression derived from Figures 5 and 6 . Table 4 indicates that the slope coefficient in the euro is significantly different from zero while this is not the case in the yen.

Insert Table 4 here 
Figures 5 and 6 lead to the impression that forecast accuracy was higher in the yen compared to the euro. This hypothesis could be derived from inspecting the vertical axis: The scale runs to 0.002 in the case of the yen and up to 0.004 in the case of the euro. We perform a test on this and are able to show that forecast accuracy is indeed significantly higher in the case of the yen. ${ }^{2}$

Hence we find two puzzling features:

1. There is a strong relationship between forecasting slope coefficient in the euro and forecast accuracy. However, this relationship is not present in the case of the yen.

2. Forecast accuracy is significantly higher in the case of the yen compared to the euro.

What explains the puzzle that in one exchange rate market, i.e., the dollareuro market, participants with high values of $\beta$ have shown better forecast accuracy, while such a correlation does not exist for the yen-dollar market? To get an answer to this question, we examine the actual exchange rate process in the next section.

\section{Actual exchange rate dynamics versus ex- pectation formation process}

In this section, we contrast the expectation formation process with the actual exchange rate process. To this end, we first estimate the exchange rate developments as a function of past exchange rate changes, i.e., we estimate

$$
s_{t+1}-s_{t}=\alpha+\beta\left(s_{t}-s_{t-1}\right)+\epsilon_{t+1} .
$$

\footnotetext{
${ }^{2}$ Mean and standard deviation of the forecast error for the yen are .0095708 and .0005532 , respectively. Mean and standard deviation of the forecast error for the euro are .0115994 and .000803, respectively. An unpaired t-test with unequal variances let to a critical value of -2.0803 for a two-sided test. Hence the $\mathrm{p}$ value is equal to $P>|t|=0.0378$.
} 
Table 5 includes the results and shows that the exchange rate of the euro and the yen exhibit interesting differences. Although we find that the exchange rate is difficult to explain with past realizations of the exchange rates, the estimates point to different characteristics in the dynamics of the two exchange rates. For the exchange rate of the yen, the estimated negative value of $\beta$ reflects a stabilizing feature so that the yen tends to depreciate after an appreciation during a six-month period and vice versa. This is different in the case of the euro. The exchange rate of the euro exhibits positive autocorrelation in returns as indicated by the estimated positive value of $B$. Hence, once the euro depreciates or appreciates during a six-month period, the process tends to continue in the same direction.

\section{Insert Table 5 here}

The findings on the actual exchange rate process are in contrast to the expectation formation process discussed in the previous section. While forecasters as a group use a mean reversion process for both exchange rates, only the yen exhibits such a tendency. Comparing the slope coefficients of the actual exchange rate dynamics with the expectation formation process suggests that the yen followed a stronger mean reversion process than expected by the forecasters. In the case of the euro exchange rate, the actual process exhibits bandwagon characteristics, while forecasters as a group expected a mean reversion for this exchange rate too. Moreover, not only did they use the wrong slope coefficient, but they also used a larger mean reversion coefficient for the euro than for the yen, for which mean reversion occurred. Thus, they strongly misjudged the actual exchange rate process of the euro/dollar, while being pretty close in the yen/dollar.

The results for the actual exchange rate process provide us also with a suggestion why the individual slope coefficients are correlated with accuracy in the euro/U.S. dollar market but such a correlation can not be found for the 
yen. As illustrated by Figure 4, forecasters were on average correct in their prediction of the actual exchange rate process of the yen, but virtually all of them underestimated the true exchange rate process of the euro.

\section{Conclusions}

In this paper, we use the WSJ poll among economists for the period 1999 - 2005 in order to compare the expectation formation processes for the exchange rates of the euro and the yen vis-à-vis the U.S. dollar and contrast them with the actual exchange rate dynamics. In addition, we investigate whether the group of forecasters is homogeneous or rather heterogeneous. Despite the limited length of the data set, it is not subject to some of the weaknesses often associated with survey data.

Our findings suggest that each individual forecaster applies a similar expectation formation process to the exchange rate of the euro and the yen vis-à-vis the dollar. For both exchange rates, expectations are based on the assumption of a stabilizing behavior. However, we find that the actual developments in the exchange rate follow a different process. The yen exhibits a process with stabilizing features which were stronger than anticipated, while the euro exhibits positive autocorrelation in returns. We also find that forecasters are fairly heterogeneous confirming earlier findings in the literature. Given that the exchange rate of the two currencies did not behave in the same manner, the similarity in the expectation formation process of individual forecasters can explain why forecasters who are successful in their projections of one exchange rate path did not necessarily perform well with respect to the other currency. 


\section{References}

Benassy-Quere, Agnes; Larribeau, Sophie; MacDonald, Ronald (2003): Models of Exchange Rate Expectations: How Much Heterogeneity?; Journal of International Financial Markets, Institutions and Money, Vol. 13(2), $113-136$.

Cho, D. W., and P. L. Hersch (1998), Forecaster Characteristics and Forecast Outcomes, Journal of Economics and Business, Vol. 50, 39-48.

De Long, J. B., A. Schleifer, A., L. H. Summers, and R. J. Waldmann (1990), "Positive Feedbacks, Investment Strategies and Destabilizing Rational Speculation", Journal of Finance, Vol. 45, 379-295.

Eisenbeis, R., D. Waggoner, and T. Zha (2002), Evaluating Wall Street Journal Survey Forecasters: A Multivariate Approach, Business Economics, Vol. 37 (3), 11-21

Elliott, G., and T. Ito (1999), Heterogeneous Expectations and Tests of Efficiency in the Yen/Dollar Forward Exchange Rate Market, Journal of Monetary Economics, Vol. 43, 435-456.

Frankel, J. A., and K. Froot (1987a), "Using Survey Data to Test Standard Propositions Regarding Exchange Rate Expectations", American Economic Review, Vol. 77, 133-153.

Frankel, J. A., and K. Froot (1987b), The Dollar as a Speculative Bubble: a Tale of Fundamentalists and Chartists, Greek Economic Review, Vol. 10, 49-102.

Frankel, J. A., and K. Froot (1990), Chartists, Fundamentalists and Trading in Foreign Exchange Markets, American Economic Review, Papers and Proceedings, 181-185.

Frankel, J. A., and A. Rose (1995), A Survey of Empirical Research on Nominal Exchange Rates, in: Grossman, S., and K. Rogoff (eds.), The Handbook of International Economics, Amsterdam.

Greer, M. R. (2003), Directional Accuracy Tests of Long-Term Interest Rage Forecasts, International Journal of Forecasting, Vol. 19, 291-298.

Ito, T. (1990), Foreign Exchange Expectations: Micro Survey Data, American Economic Review, Vol. 80, 434-449. 
Keane, Michael P.; Runkle, David E. (1990): Testing the Rationality of Price Forecasts: New Evidence from Panel Data, in: American Economic Review, vol. 80, no. 4, $714-735$.

Kolb, R. A.; Stekler, H. O. (1996): Is There a Consensus among Financial Forecasters?, International Journal of Forecasting, Vol. 12(4), 455 564.

Laster, David; Bennett, Paul; Geoum, In Sun (1999): Rational Bias in Macroeconomic Forecasts, in: Quarterly Journal of Economics, vol. 114, no. 1, $293-318$.

Leitner, Johannes; Schmidt, Robert; Bofinger, Peter (2003): Biases of professional exchange rate forecasts: psychological explanations and an experimentally based comparison to novices Würzburg Economic Papers \#39.

MacDonald, R., and I.W. Marsh (1996), Currency forecasters are heterogeneous: confirmation and consequences, Journal of International Money and Finance, Vol. 15, 665-685.

Menkhoff, L. (1998), The Noise Trading Approach - Questionnaire Evidence from Foreign Exchange, Journal of International Money and Finance, Vol. 17, 547-564.

Menkhoff, L. (2001), Short-Term Horizons in Foreign Exchange? Survey Evidence from Dealers and Fund Managers, Kyklos, Vol. 54, 27-47. 
Table 1: Test for Unbiasedness

\begin{tabular}{|l|c|c|}
\hline & Yen/Dollar & Dollar/Euro \\
\hline & $\begin{array}{c}\text { Specification I } \\
\text { Pooled OLS }\end{array}$ & $\begin{array}{c}\text { Specification II } \\
\text { Pooled OLS }\end{array}$ \\
\hline Intercept & $-.0070^{* *}$ & $.0171^{* * *}$ \\
& $(.0035)$ & $(.0033)$ \\
\hline Beta & -.0735 & $-.1319^{* *}$ \\
$E_{i, s}\left[s_{t+1}\right]-s_{t}$ & $(.0650)$ & $(.0538)$ \\
\hline Goodness of Fit & $R^{2}=.0028$ & $R^{2}=.0114$ \\
\hline No. of Obs. & 523 & 523 \\
\hline
\end{tabular}

Note: Regression results for the equation $s_{t+1}-s_{t}=\alpha+\beta\left(E_{i, t}\left[s_{t+1}\right]-s_{t}\right)+\epsilon_{i, t+1}$. Standard error in parentheses. $* * *(* *, *)$ indicates significance on a $1 \%(5 \%, 10 \%)$ confidence level.

Table 2: Test for Orthogonality

\begin{tabular}{|c|c|c|c|c|}
\hline & Yen/Dollar & \multicolumn{3}{|c|}{ Dollar/Euro } \\
\hline & $\begin{array}{l}\text { Specification I } \\
\text { Pooled OLS }\end{array}$ & $\begin{array}{l}\text { Specification II } \\
\text { Pooled OLS }\end{array}$ & $\begin{array}{l}\text { Specification III } \\
\text { Fixed Effects }\end{array}$ & $\begin{array}{l}\text { Specification IV } \\
\text { Random Effects }\end{array}$ \\
\hline Intercept & $\begin{array}{c}-.0181^{* * *} \\
(0043)\end{array}$ & $\begin{array}{l}.0117^{* * *} \\
(.0044)\end{array}$ & $\begin{array}{c}.0120^{* * *} \\
(.0043)\end{array}$ & $\begin{array}{l}.0120^{* *} \\
(.0049)\end{array}$ \\
\hline Beta & $\begin{array}{c}-.1461^{* * *} \\
(.0553)\end{array}$ & $\begin{array}{l}.3231^{* * *} \\
(.0541)\end{array}$ & $\begin{array}{c}.2993^{* * *} \\
(.0544)\end{array}$ & $\begin{array}{c}.3193^{* * *} \\
(.0536)\end{array}$ \\
\hline Modell Fit & $R^{2}=.0132$ & $R^{2}=.0640$ & $\begin{array}{c}R^{2} \text { within }=.0603 \\
R^{2} \text { between }=.1975 \\
R^{2} \text { overall }=.0640\end{array}$ & $\begin{array}{c}R^{2} \text { within }=.0603 \\
R^{2} \text { between }=.1975 \\
R^{2} \text { overall }=.0640\end{array}$ \\
\hline $\begin{array}{l}\text { Various Test } \\
\text { Statistics }\end{array}$ & - & - & $\begin{array}{c}\mathrm{F}(49,472)=1.41 \\
\text { Prob }=0.041\end{array}$ & $\begin{array}{c}\text { Hausman } \\
\text { Prob }>\text { ch } i 2=0.5009\end{array}$ \\
\hline No. of Obs. & 523 & 523 & 523 & 523 \\
\hline No. of Groups & - & - & 50 & 50 \\
\hline
\end{tabular}

Note: Regression results for the equation $s_{t+1}-E_{i, t}\left[s_{t+1}\right]=\alpha+\beta\left(s_{t}-s_{t-1}\right)+\epsilon_{i, t+1}$. Standard error in parentheses. $* * *(* *, *)$ indicates significance on a $1 \%(5 \%, 10 \%)$ confidence level. 
Table 3: Regression Results for the Extrapolative Expectation Hypothesis

\begin{tabular}{|c|c|c|c|c|}
\hline & \multicolumn{2}{|c|}{ Yen/Dollar } & \multicolumn{2}{|c|}{ Dollar/Euro } \\
\hline & $\begin{array}{l}\text { Specification I } \\
\text { Fixed Effects }\end{array}$ & $\begin{array}{l}\text { Specification II } \\
\text { Random Effects }\end{array}$ & $\begin{array}{l}\text { Specification III } \\
\text { Fixed Effects }\end{array}$ & $\begin{array}{l}\text { Specification IV } \\
\text { Random Effects }\end{array}$ \\
\hline Intercept & $\begin{array}{l}.0091^{* * * *} \\
(.0022)\end{array}$ & $\begin{array}{l}.0095^{* *} \\
(.0042)\end{array}$ & $\begin{array}{l}.0038^{*} \\
(.0022)\end{array}$ & $\begin{array}{l}.0038 \\
(.0048)\end{array}$ \\
\hline Beta & $\begin{array}{c}-.0694^{* *} \\
(.0282)\end{array}$ & $\begin{array}{c}-.0674^{* *} \\
(.0282)\end{array}$ & $\begin{array}{c}-.2127 * * * \\
(.0281)\end{array}$ & $\begin{array}{c}-.2152^{* * *} \\
(.0280)\end{array}$ \\
\hline Modell Fit & $\begin{array}{c}R^{2} \text { within }=.0127 \\
R^{2} \text { between }=.0319 \\
R^{2} \text { overall }=.0076\end{array}$ & $\begin{array}{c}R^{2} \text { within }=.0127 \\
R^{2} \text { between }=.0319 \\
R^{2} \text { overall }=.0076\end{array}$ & $\begin{array}{c}R^{2} \text { within }=.1080 \\
R^{2} \text { between }=.0580 \\
R^{2} \text { overall }=.0833\end{array}$ & $\begin{array}{c}R^{2} \text { within }=.1080 \\
R^{2} \text { between }=.0580 \\
R^{2} \text { overall }=.0833\end{array}$ \\
\hline $\begin{array}{l}\text { Various Test } \\
\text { Statistics }\end{array}$ & $\begin{array}{c}\mathrm{F}(49,472)=3.81 \\
\text { Prob }=0.00\end{array}$ & $\begin{array}{c}\text { Hausman } \\
\text { Prob }>\text { chi } 2=0.4308\end{array}$ & $\begin{array}{c}\mathrm{F}(49,472)=4.84 \\
\text { Prob }=0.00\end{array}$ & $\begin{array}{c}\text { Hausman } \\
\text { Prob }>\text { chi } 2=0.4308\end{array}$ \\
\hline No. of obs. & 523 & 523 & 523 & 523 \\
\hline No. of Groups & 50 & 50 & 50 & 50 \\
\hline
\end{tabular}

Note: Regression results for the equation $E_{i, t}\left[s_{t+1}\right]-s_{t}=\alpha+\beta\left(s_{t}-s_{t-1}\right)+\epsilon_{i, t+1}$. Standard error in parentheses. $* * *(* *, *)$ indicates significance on a $1 \%(5 \%, 10 \%)$ confidence level.

Table 4: Relationship Between Individual Slope Coefficients and Forecast Accuracy

\begin{tabular}{|l|c|c|}
\hline & Yen & Euro \\
\hline Intercept & $\begin{array}{c}.0093^{* * *} \\
(.0005)\end{array}$ & $\begin{array}{c}.0092^{* * *} \\
(.0012)\end{array}$ \\
\hline Beta & $\begin{array}{c}-.0042 \\
(.0026)\end{array}$ & $\begin{array}{c}-.114^{* *} \\
(.0048)\end{array}$ \\
\hline Model Fit & $R^{2}=.0529$ & $R^{2}=.1284$ \\
\hline No. of Obs. & 50 & 50 \\
\hline
\end{tabular}

Note: Standard error in parentheses. $* * *(* *, *)$ indicates significance on a $1 \%(5 \%, 10$ $\%)$ confidence level.

Table 5: Regression Results for the Actual Exchange Rate Process

\begin{tabular}{|l|c|c|}
\hline & Yen/Dollar & Dollar/Euro \\
\hline Intercept & .0091 & .0125 \\
& $(.0247)$ & $(.0241)$ \\
\hline Beta & -.2356 & .0883 \\
& $(.3102)$ & $(.2948)$ \\
\hline Model Fit & $R^{2}=.0545$ & $R^{2}=.0089$ \\
\hline No. of Obs. & 12 & 12 \\
\hline
\end{tabular}

Note: Regression results for the equation $s_{t+1}-s_{t}=\alpha+\beta\left(s_{t}-s_{t-1}\right)+\epsilon_{i, t+1}$. Standard error in parentheses. ${ }^{* * *}(* *, *)$ indicates significance on a $1 \%(5 \%, 10 \%)$ confidence level. 
Figure 1: Participation Frequency of the Forecasters

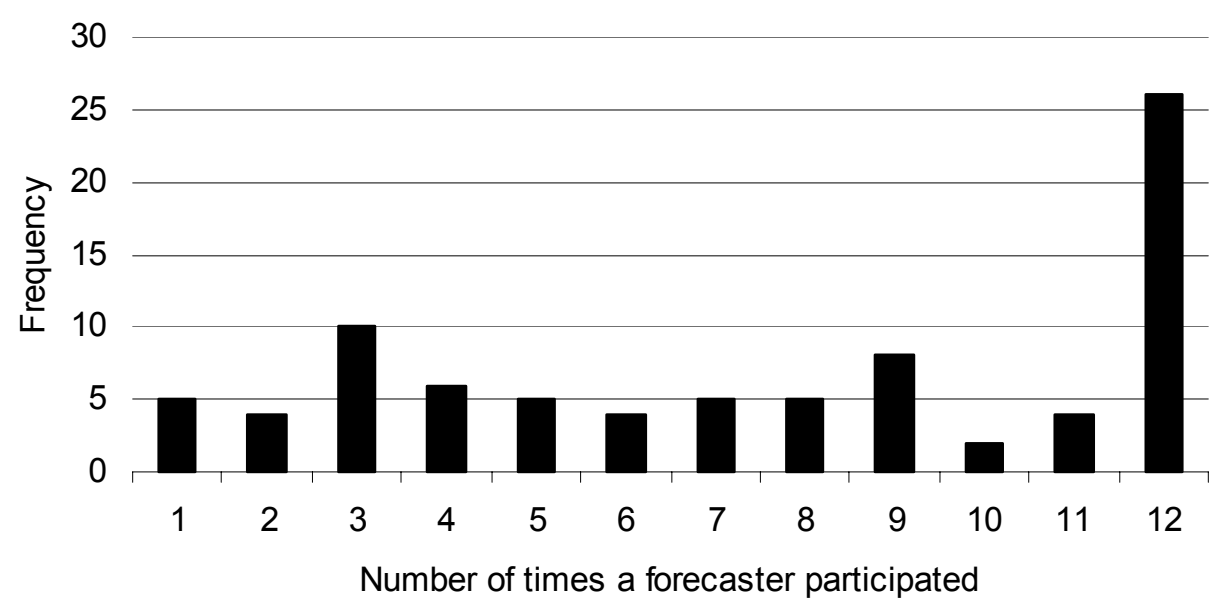


Figure 2: Exchange Rate Dynamics and Exchange Rate Expectations

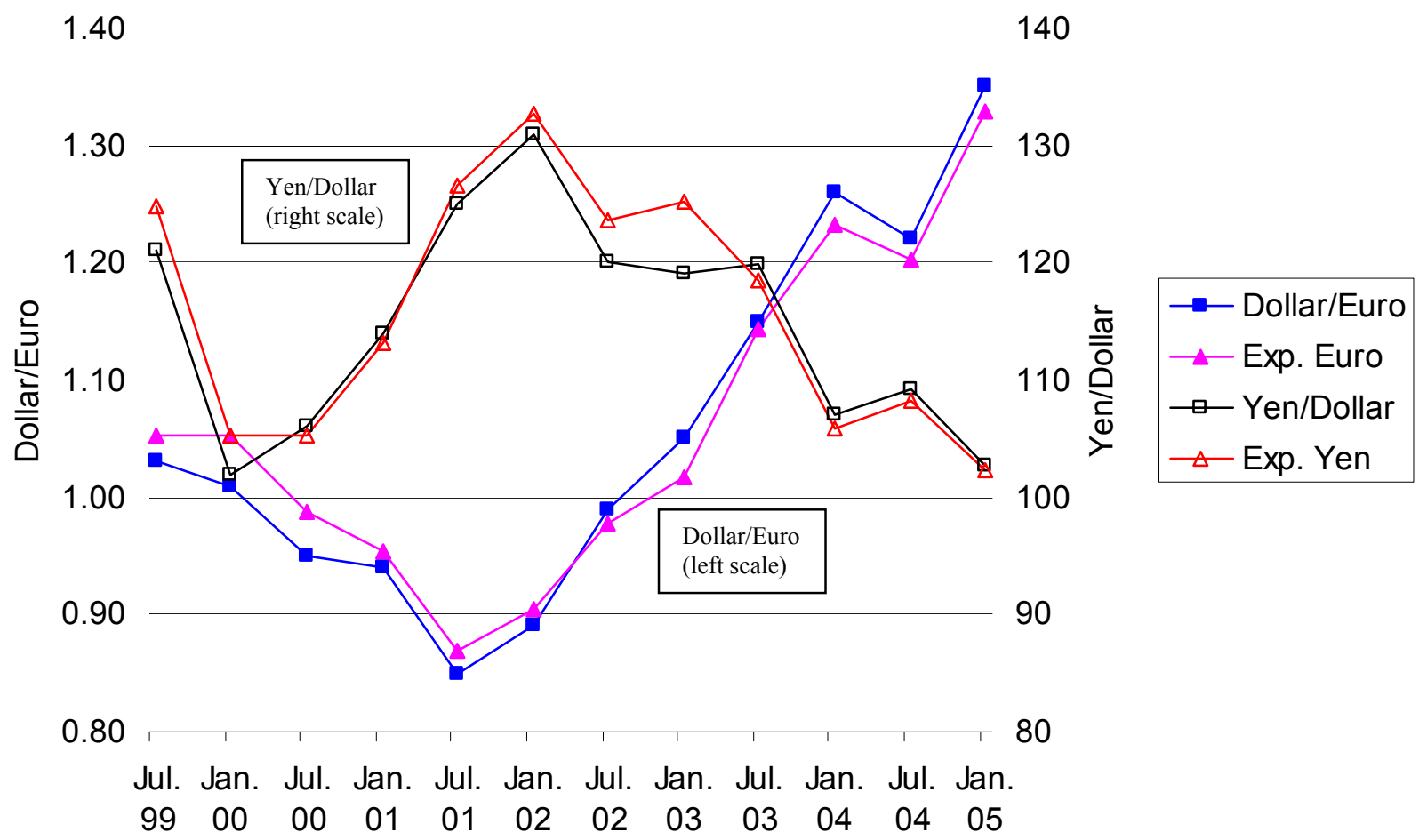

Note: Figure 2 shows the exchange rate at time $t\left(s_{t}\right)$ as well as the mean of the 6-month exchange rate expectations of the different forecasters at time $t\left(\bar{E}_{t}\left[s_{t+1}\right]\right)$. 
Figure 3: Individual Exchange Rate Expectations in the Dollar/Euro and the Yen/Dollar Market

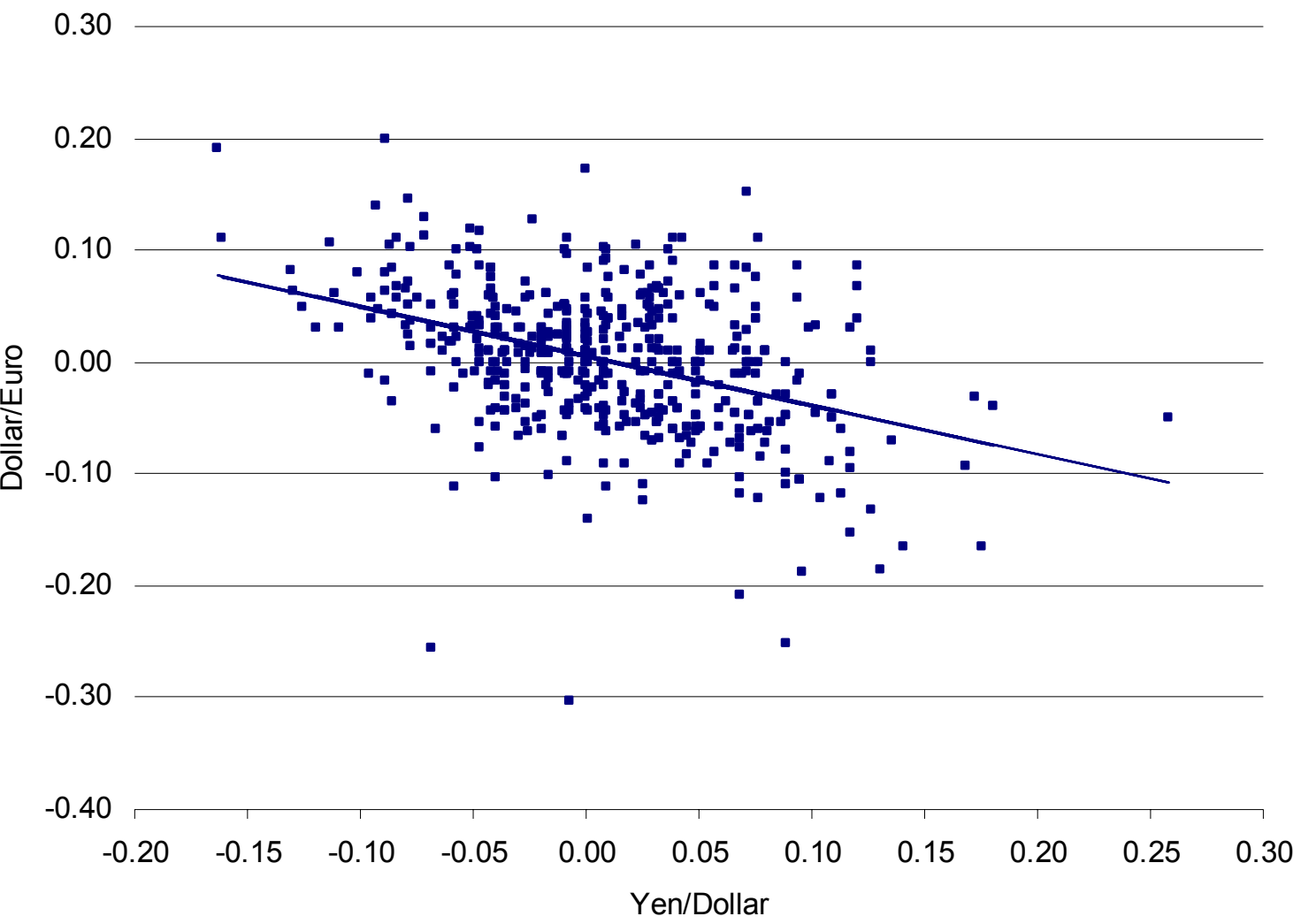

Note: Figure 3 shows the expected relative exchange rate change $\left(E_{i, t}\left[s_{t+1}\right]-s_{t}\right)$ for the Dollar/Euro exchange rate as well as for the Yen/Dollar exchange rate. The relationship between the two variables under consideration has the following characteristics:

Dollar/euro $=0.0053^{* *}-0.4407^{* \star *}$ Yen/Dollar No. of Obs $=523$, Goodness of Fit: $R^{2}=0.1647$ (.0024) (.0486) 
Figure 4: Individual Slope Coefficients in the Expectation Formation Process for the Euro and the Yen

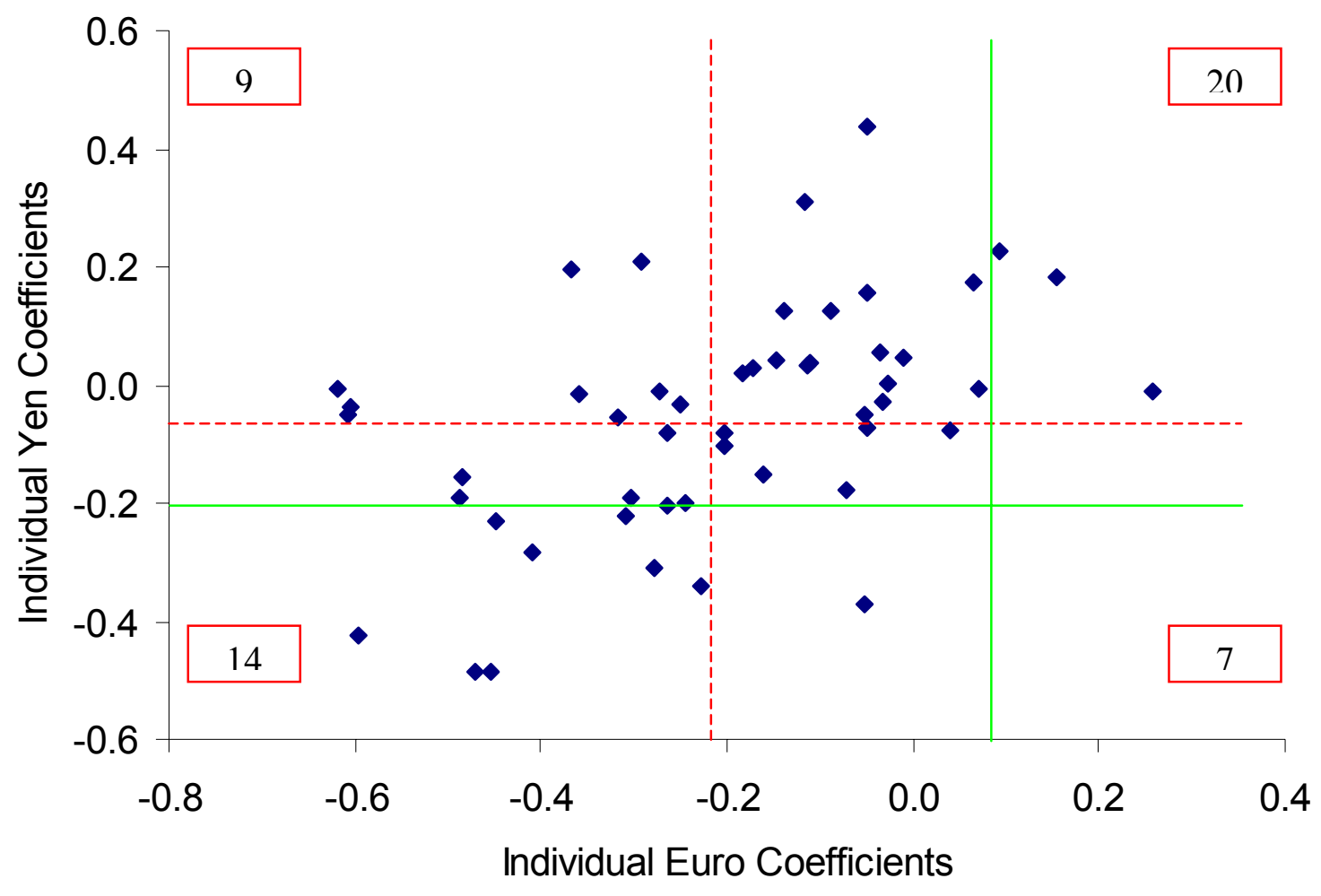

Note: Figure 4 shows the relationship between the individual slope coefficients in the Euro and the Yen. The red (dashed) lines result from the expectation formation process and show the mean of the slope coefficient given in Table 3. The green (solid) lines represent the exchange rate process, estimated in Table 5. 
Figure 5: Individual Slope Coefficients and Forecast Accuracy in the Euro-Dollar Market

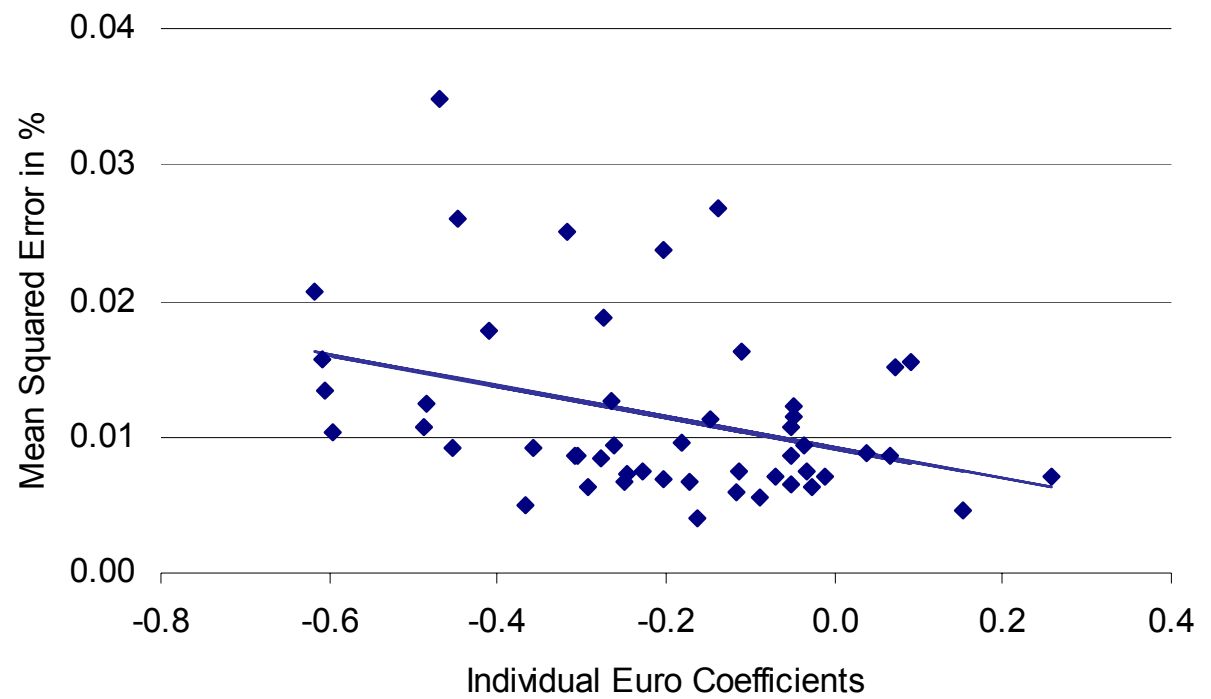

Figure 6: Individual Slope Coefficients and Forecast Accuracy in the Yen-Dollar Market

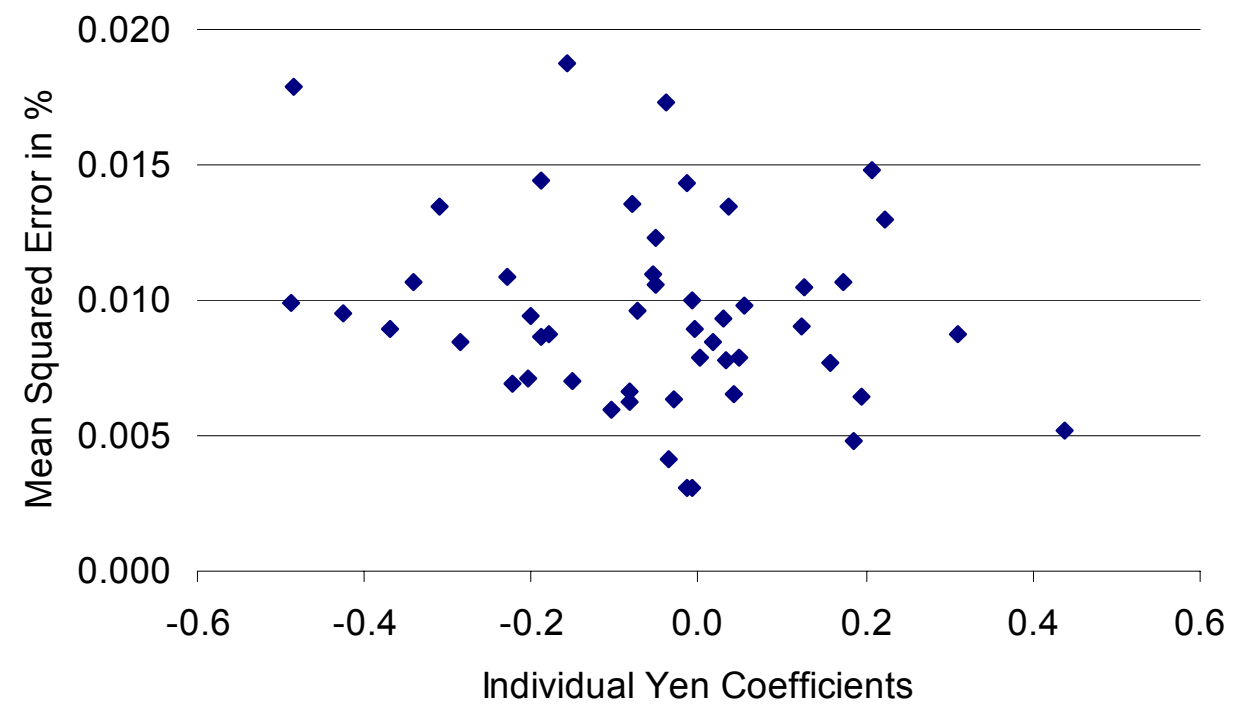

Note: Figure 5 and Figure 6 show the relationship between the individual exchange rate formation process and the individual forecast accuracy. Regression results, presented in Table 4 show a close relationship between the variables under consideration for the Euro, but not for the Yen. Consequently, we only inserted a regression line in Figure 5. 